\title{
Research on Anti-Seepage Layer Performance of Landfill Site
}

\author{
Sun Xue-jing ${ }^{1, a}$, Wang Zhan-hua ${ }^{2, b}$ \\ 1Jilin Jianzhu University, Changchun, Jilin Province, China \\ 2 Jilin Jianzhu University, Changchun, Jilin Province, China \\ a239632769@qq.com, b57203848@qq.com
}

Keywords: landfill; modified clay liner; silica fume; anti-cracking; hydraulic conductivity Abstract. To reduce the permeability of clay liner, and make it has anti-cracking performance. Permeability and anti-cracking properties were studied on different Silica fume added to clay liner. $0 、 10 \% 、 15 \%, 20 \% 、 15 \%, 30 \%$ of the clay is replaced by silica fume at optimum water contents. It is shown by test results that permeability and width of crack is increased with increasing content of silica fume between 0 and $10 \%$, permeability and width of crack is reduced with increasing content of silica fume between $10 \%$ and $20 \%$, permeability and width of crack is increased with increasing content of ash between $20 \%$ and $30 \%$, permeability and width of crack is the minimum is found for the $20 \%$ silica fume added to clay liner. According to the experimental data and experimental results, the best proportion is $20 \%$, permeability is directly proportional to width of crack.

\section{Introduction}

With the rapid development of social economy and urbanization, landfill in cities has become one of the hot issues in environmental protection. At present, the main method to treat municipal solid waste is landfill[1]. However, due to the influence of external factors ( e.g. rainwater, surface water and groundwater ), this method causes solid waste garbage to produce leachate which is harmful to heavy metals and has greater toxicity and directly affects environmental pollution. In this paper the problem of anti-seepage layer of garbage mainly is studied. The use of fly ash and clay in the process of landfill is discussed to solve the problem of cracking of anti-seepage layer through theoretical analysis and experimental research.

Landfilling is one of the main means in disposing municipal solid wastes. The design of liner systems in landfill is vital important and the materials for liner systems including high-density polyethylene and clayed soils at present[2-3]. High-density polyethylene poses a high performance in keep penetrating, but it ages easily and is inclined to abrade in the construction. The natural clay is widely used in the liner systems in the landfills due to its absorbing ability, plasticity, ion exchange capacity, low permeability and low costs. However, the liner system may be easily affected by the hydraulic pressure in the landfill generating high permeability and high expansive potentials causing instability problem in some cases: in the change of volume and pressure, some part of the liners cannot change accordingly and thus lead to the cracks[4-5]. When this happens, it needs to perforate and dig out great amounts of soil which is time-consuming and costing with undesirable results. Based on these, the aim of this thesis mainly focuses on the clayey soil-silica fume mixture barrier's properties of permeability and desiccation cracks.

\section{Experimental Materials and Methods}

Experimental Equipment. The experiment is divided into two parts. The first part is the dynamic simulation test. In this part, the variable head penetration device and the permeation vessel will be used. As shown in Figure 1. The second part is the simulation test of dry shrinkage cracking. In this part, the light compaction instrument, the organic glass column 6 and other common laboratory equipment will be used. 


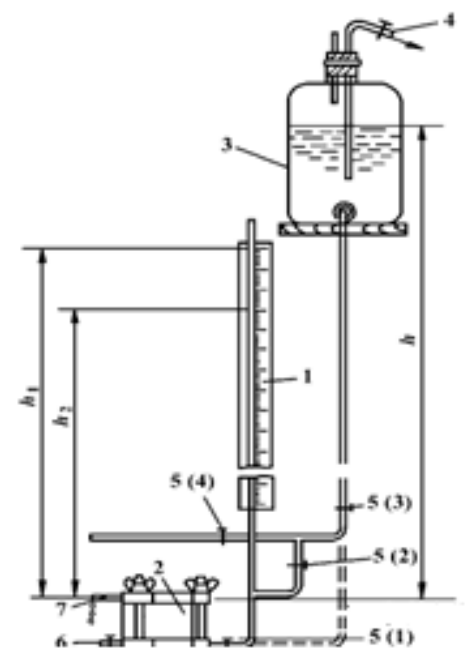

Fig1.Schematic diagram of variable head permeability test device

1 - Water power tube 2- Infiltration vessel 3- Water bottles, the capacity is 5000ml 4- Connecting water source 5. Stop clip 6. Exhaust pipe 7

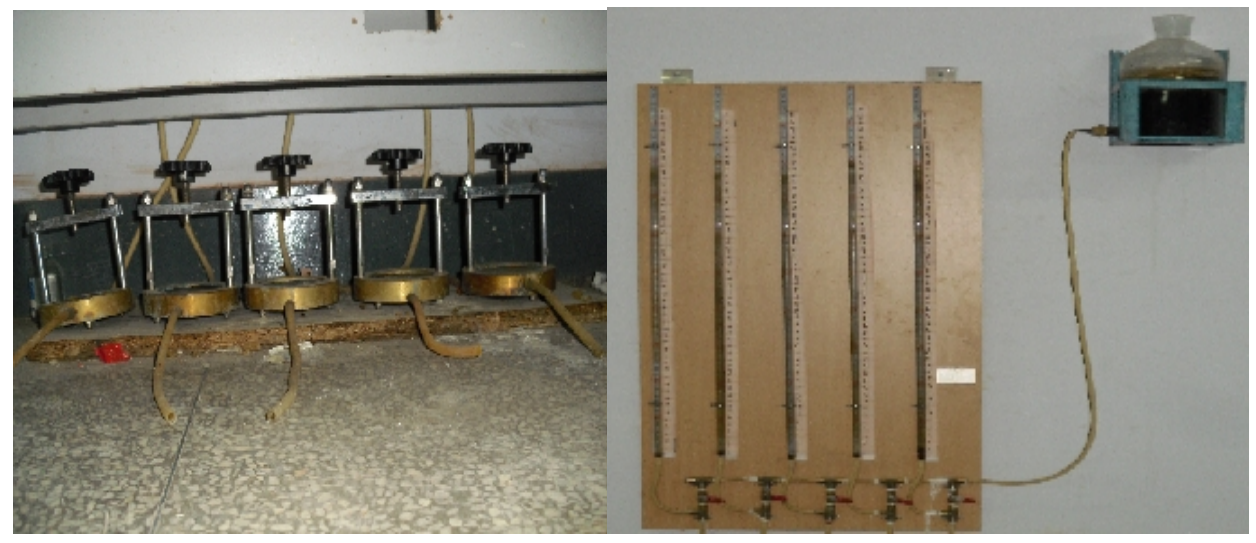

Fig2. Physical diagram of variable head infiltration device

In this experiment, clay and silica fume are used as experimental materials. The clay was taken from the West Changchun City Luyuan District township. The clay will then be dried naturally and then grinded. Silica fume is taken from Beijing Bondein synthetic material research institute. The physical properties of silica fume are listed in Table 1. As can be seen from table 1, the main component of silica fume is $\mathrm{SiO} 2$. There are also a small amount of $\mathrm{Al} 2 \mathrm{O} 3, \mathrm{Fe} 2 \mathrm{O} 3, \mathrm{CaO}$ and $\mathrm{MgO}$ are included in the silica fume The surface area of silica fume is very large, and it has strong surface activity. Silica fume can react with $\mathrm{Ca}(\mathrm{OH})_{2}$ to form hydrated calcium silicate gel under alkaline conditions, and it is a kind of highly active volcanic ash. In addition, When the silica fume is formed, phase transition in the process of the role of surface tension, none crystalline phase and amorphous spherical particles are performed. It relatively smooth surface, some are a plurality of spherical particles of aggregate stick together. The small spherical body can play the role of lubrication.

Table 1 Chemical composition of the silica fume and clay

\begin{tabular}{|c|c|c|c|c|c|}
\hline component & $\mathrm{SiO} 2(\%)$ & $\mathrm{Al} 2 \mathrm{O} 3(\%)$ & $\mathrm{Fe} 2 \mathrm{O} 3(\%)$ & $\mathrm{CaO}(\%)$ & $\mathrm{MgO}(\%)$ \\
\hline clay & 66.1 & 12.33 & 3.74 & 5.03 & 1.54 \\
\hline Silica fume & 94.05 & 0.76 & 0.68 & 0.75 & 0.25 \\
\hline
\end{tabular}

Test Methods. Natural air-dried soil samples and fly ash is mixed according to a certain percentage. Light compaction test is made. Fly ash and clay is passed through $2 \mathrm{~mm}$ sieve respectively, the sieved soil samples are mixed and the air-dry moisture content of soil samples is tested. The optimum moisture content is estimated, and a difference of about $2 \%$ according to the moisture content of a 
preparation (not less than five patterns). There are two water content is greater than the plastic limit, two water content is less than the plastic limit, one moisture content is close to the plastic limit. The amount of water is calculated according to relevant formula. A certain percentage of soil samples will be mixed and then spray the required amount of water, and then mix into the bag for 24 hours. The mixed soil sample is compacted by the light compaction meter, and the moisture content and dry density of each compacted soil are calculated according to formula. The relationship between optimal moisture content and the maximum dry density is obtained by the curve.

According to the standard of pollution control standard (GB16889-2008) of the waste landfill site, the variable head permeability test was carried out according to GB/T 50123. The variable head permeability test is to determine the permeability coefficient of the soil by measuring the seepage quantity of a certain time under the change of the pressure of the soil. TST-55 type variable head permeability device is adopted.

Before the variable head permeability test, the first step is to mix the air and dry soil sample. Secondly, moisture content of soil samples is calculated according to the optimum water content. Third step soil sample was added to the appropriate amount of water and was 24 hours of maintenance. Then the soil sample is compacted, and the ring knife is cut into soil sample, and the ring knife with soil sample is put into the vacuum device to carry out the gas pumping saturation. At last, the saturated model is loaded into the hydraulic system, and the water level in the variable head is changed to a high degree, the head and the time are recorded to be stable, the variable head permeability coefficient is calculated according to Darcy's law.

The different proportions of modified clay $(10 \%, 15 \%, 20 \%, 25 \%, 30 \%)$ were used to make it in the best water content state, which was maintained at $24 \mathrm{~h}$. Then it is placed in an organic glass column, so that the water content of the sample can reach the maximum possible saturation in the static water pressure head; and then the sample is taken out under the condition of the laboratory. The cracking of each specimen was observed and recorded after 20 days.

\section{Test Results and analysis.}

The permeability coefficient of silica fume modified clay was determined by varying the head penetration test. When the pattern has been saturated with water and the water has reached a steady state, the change of the instrument data has been observed and recorded for five consecutive days. The results of the experiment are shown in table 2.

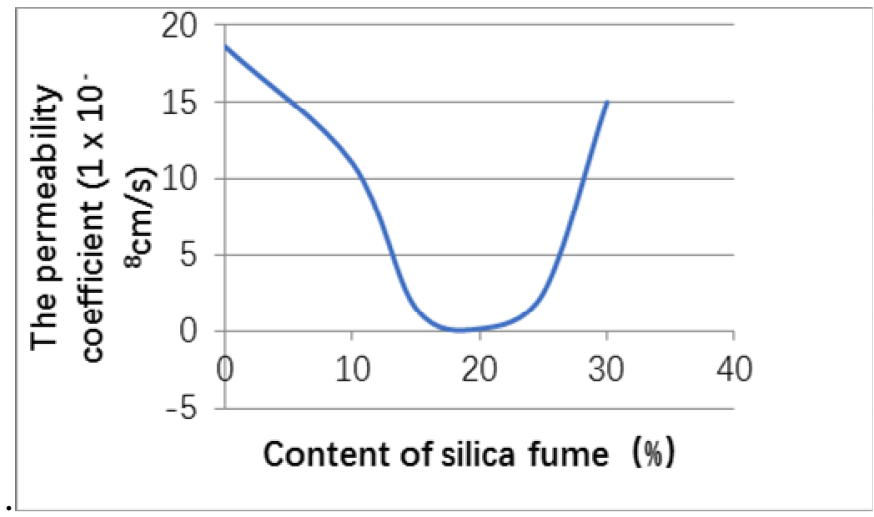

Fig.3 permeability coefficient of modified clay with different silica fume

The change of permeability coefficient of modified clay with different silica fume ratio can be observed in Figure 4-1. In the ratio of $10 \% \sim 20 \%$, the coefficient of permeability decreases with the increase of the content of silica fume. In $20 \% \sim 30 \%$, the permeability coefficient increases with the increase of the content of silica fume. That the permeability coefficient reached the minimum at $20 \%$. And the best point appeared in $20 \%$ of the ratio of silica fume. 
In this experiment, the dry shrinkage cracking of the modified clay with different content of silica fume was studied and analyzed in terms of the number of cracks. The results of the experiment are shown in table 2.

From the crack length and the number of cracks, at the end of the experiment, the clay surface appeared as long as $121 \mathrm{~mm}$ cracks, and the number of modified clay is also the largest, reaching 9 . Crack length and the number of the crack from the point of view, at the end of the experiment, single natural clay surface appeared up to $121 \mathrm{~mm}$ crack, crack 9 . The width of crack is $2 \mathrm{~cm}$. With the increase of silica fume quantity, the fracture number decreased significantly, and in $20 \%$ dosage of silica fume modified clay liner only existing 2 crack, the length of about $20 \mathrm{~mm}$. The maximum width is about $1 \mathrm{~mm}$, and the $30 \%$ silica fume content of clay liner does not appear cracks. It can be seen that the appropriate addition of silica fume, to a large extent, can reduce the dry shrinkage cracking of clay.

Table 2 Cracking condition of different ratio of silica fume modified clay

\begin{tabular}{|l|l|l|l|l|l|l|}
\hline Silica Fume Content & 0 & $10 \%$ & $15 \%$ & $20 \%$ & $25 \%$ & $30 \%$ \\
\hline Maximum Width(mm) & 20 & 11 & 5 & 1 & 0 & 0 \\
\hline Maximum Length(mm) & 121 & 50 & 20 & 5 & 0 & 0 \\
\hline Number of Bars & 9 & 5 & 5 & 1 & 0 & 0 \\
\hline
\end{tabular}

\section{Conclusions.}

By using the variable head permeability test, it can be concluded that the optimum adding amount of the clay liner can be improved by adding silica fume, which is $20 \%$.Experimental study on dry shrinkage cracking of modified clay liner shows that the number, length and width of crack are smaller with the increase of silica fume content (0-30\%). So it can be seen that silica fume can prevent dry shrinkage cracking of clay liner. The results show that the compacted clay samples with silica fume exhibit quite low permeability, swelling pressure and significantly high compressive strength as compared to raw clay samples under optimum moisture content and maximum dry density, particularly in the contents of $20 \%$. Thus, silica fume appears to be promising for construction material of liners subjected to leachate in solid waste containment systems.

\section{Acknowledgements}

This work was financially supported by Jilin province education department " 13th Five - Year Plan" science and technology research project ([2016 ]No159).

\section{References}

[1] Ekrem Kalkan: Applied Clay Science Vol. 43 (2009), p.25

[2] Caijun Shi:Waste Management Vol. 25 (2005), p. 231

[3] Ekrem Kalkan, Suat Akbulut:Journal of Engineering Geology Vol.73(2004),p.145

[4] Ekrem Kalkan: Journal of Applied Clay Science Vol.43(2009), p.296

[5] Y.Y.Tay, D.I.Stewart, T.W.CouSens:Journal of Engineering Geology Vol. 60 (2001) ,p.263

[6] N.Yesiller, C.J.Miller,G. Inci,K. Yaldo: Journal of Engineering Geology Vol.57 (2000),p.105

[7] M.H.T. Rayhani , E.K. Yanful , A. Fakher: Journal of Engineering Geology Vol.97 (2008),p.25

[8] Shi C ,Booth R: Waste Management Vol.25(2005),p.231. 